\title{
Reading Community and Culture in Translated Fiction: Representation of the Cochin-Creole Society in Jeevichirikkunnavarkku Vendiyulla Oppees or Requiem for the Living.
}

DIVYA N.

\section{Abstract}

Translated fiction embodies not mere tales but history, sociobiography and culture. The proposed paper inspired by Johny Miranda's Jeevichirikkunnavarkku Vendiyulla Oppees: Requiem for the Living intends to and analyse the fictive text from the historical and socio-cultural perspectives. The paper explores the multiple aspects, nuances and subtleties associated with the narrative fictionalizing of Cochin Creole community and culture manifested in the selected text. How does the vociferous textual assertion inherent in the literary portrayal of the hybrid world of Cochin-Creole community enables a re-framing of the perspectives associated with gender, caste and ethnicity in the culture of Kerala? What are the discrepancies and disjunctions in the fictive rendering that constitute a difference in the narrative framework, making the proposed text different from other community narratives? These will form the key thematic concerns which the paper would analyse in the due course.

Keywords: Cochin-Creole, Culture, Cosmopolitan, Community, Ethnicity, Identity.

Portuguese Creole community has garnered significant historical and fictive contemplation in the Kerala "cultural" memory. Momentous and interesting fictive endeavours though diminutive in number have emerged in relation to the portrayal of the Cochin -Creole life. This study focuses on the multiple subtleties and nuances employed in the narrative rendering of the social and cultural history of the Cochin 
Reading Community and Culture in Translated Fiction...

Creole lives in the translated narrative Jeevichirikkunnavarkku Vendiyulla Oppees: Requiem for the Living.

An overview of the social and cultural history of the CochinPortuguese natives demands an unravelling of their subjective past through a kaleidoscopic analysis of their collective situation. The study assumes the responsibility of furnishing a critical and objective evaluation of historical imagination at a global level through translation. It interrogates the historical significance of the "topographic narrative" portraying an ethnographic fictive account of the Cochin-Creole community, the descendants of the Cochin natives and the colonial Portuguese inhabitants of Kerala. The narrative depicts the life story of the Cochin-Creole community through the family of Josy Pereira or Osha comprising of his wife Jacintha, father named Franso Pereira, mother or Mamma called Petrina Pereira, sister Ida and grand-parents Pappanji called Caspar, Mammanji called Juana or Joona and father in law Thomas or Thummai. Osha's quest for the lock of a key that he receives from a grave and accompanied with the parallel incidents generating communal reminiscences and the subsequent loss of the key culminating in Osha's paralysis constitute the narrative framework.

\section{Community Narratives, Landscape and History in Translation}

Community narratives have ascertained and acclaimed an inter-textual articulation of social life facilitating the simultaneous inter-weaving of history and fiction. Societal history exemplified through the individual lives has perpetually refurbished the ethnographic memory of both dead and living pasts. The translated version of the narrative endeavours to preserve the communal spirit through retaining the collective names. It "captures the life of the Anglo-Indian 


\section{Divya N.}

Latin Catholics of central Kerala, who have lived through great historical, political, and social upheavals" (Miranda 2013: xi). It undertakes the task of familiarising a comparatively unknown community before a global readership. The translator observes that "In many ways, the world described in the novella is unfamiliar even to readers of the original Malayalam" (Jose 2013: xviii).The text accouts for a historically realistic picture of the Anglo-Indian society and culture accentuating their heterogeneous origins and their present subversive position. According to him, "They may call themselves Anglo-Indian and carry outlandish surnames that stick out like tails, but the fact is that majority of them remain backward and poor" (Miranda 2013: xii).

The family history commences with the story of Pappanji's papa or the narrator Osha's great grandfather who arrived at Ponjikkara and settled in Mattancherry. The coastal landscape of Mattancherry and Ponjikkara emerges as the major historical locations and the "chronotope" of the narrative signifying the "intrinsic connectedness of temporal and spatial relationships" (Bakhtin1981: 84).The regional framework of the novella substantiates Johny Miranda's acknowledgment of the influence of the early writer Ponjikkara Rafi on his works at the beginning of his literary career.

The narrative recognises the historical presence and documentation of multiple communities in the social history of the landscape. "Over the centuries, there have been several references to mixed communities besides the better-known Eurasians, called variously as Topasses, Parankis, Feringhees, Mundukaar, and so on, especially in Kochi, who accompanied and served the Portugese and the Dutch, were legally under them, worked in trades and as labourers, and set up local families" (Devika 2013: xxiii-xxiv). Contrary to the escalating endeavours to homogenise the multiple identities the narrative 
Reading Community and Culture in Translated Fiction...

focuses on the specific history and the past of Parankis or the community of Cochin creoles.

The fictive portrayal of the community identity through the historical location of Kochi positions the narrative in the broader framework of temporal and spatial imagination. Howsoever compared to the early community narratives the imaginative universe of the narrative based "on Kochi and on the life of Latin Catholics was not born of a conscious urge to write a Kochi novel ... The urge instead was to write a novel ... [based on their] lived experiences [and hence] Kochi was not the focal point of imagination, but a medium" (Thomas 2015: para.6)

The translated fiction transforms the geographical history into a psychological one, articulating the emotional affinities to the community and family past thus facilitating an interjection and interpolation of the individual histories. The narrator Osha's family history becomes tied up with the history of the land as occasional mnemonic digressions into a distinct community past and lineage dominate the narrative.

Dissimilar to the mainstream history that attributes the lineage of Parankis chiefly to their Portugese European ancestor, some critics opine that "the Parankis bear traces of more than two cultures; among them are traces of not only the Portuguese culture and the non-Sanskritized and lower-caste cultures prevalent in Kerala, but also elements from South-east Asia, especially Java and Malaca, which were prominent centres of Dutch and Portuguese trade in the sixteenth and seventeenth centuries" (Devika 2013: xxiv). Analogous to her observation the narrative description of the "common features of the men" in Osha's family comprises of "dark skin, rough, shrunken cheeks, bloated eyelids, centipede moustache, 
Divya N.

baldness, rotten teeth, potbelly, and dwarfish build" (Miranda 2013: 12).

The familial description of the Cochin-Creole community subtly implies the practice of the mixed marriages and miscegenation where the Portuguese men married the native lower caste women of Cochin. Reflections on being the descendants of a mixed lineage dominate the psyche of the protagonists and their actions. Osha's consensus to marry Jacintha, a Latin Mappilah Christian becomes attributed to his unconscious inclination and awareness of hybrid lineage. The relationship becomes mnemonic of the history of miscegenation and the complex reproduction of ancestry. The protagonist Osha "faces upfront the reality of the impossibility of asserting miscegenated identities in a culture so obsessed with purity of birth" (Devika 2013: xxix).

Exploration on the cultural politics and intricacies of representation assumes relevance in the context of hegemonic and subversive identity manifestations. The narrative explicitly elucidates the influence of the Portuguese invasion on the diversified Kerala culture and society. "The effects of Portugese impact on traditional Kerala society were indeed farreaching, especially since it had to face a social and religious system which was radically different" (A. Menon 1967: 235).

However, contrary to the early community novels the narrative doesn't bear the burden of "explicit desire for social reform, as were the early nineteenth-century subaltern novels. Nor is the anticipated reader a member of the Paranki community, quite unlike the late nineteenth-century subaltern novel which directly addressed ... [the] members of the oppressed castecommunities" (Devika 2015: 8). The authorial endeavour is to provide a realistic community history through the mouthpiece of the protagonist Osha and not an exotic version rooted in the 
Reading Community and Culture in Translated Fiction...

subjective conceptualisation of an imaginative "glorious" period. The novella also avoids any didactic form of narration accentuating the need for a compulsive revival of the past.

\section{Em(bodying) Historicity}

Dressing emerges as a major cultural resource of identity symbolising the appropriation of an alien history into the folds of the native dissolution through the enactment of bodily covering. The protagonists embrace a regional dress code despite their hybrid affinity thereby signifying the complex and simultaneous existence of multiple identities. Osho delineates that "Though we were Parankis, the men in our family weren't the kind who wore trousers. Instead they wore the mundu and the half-sleeved shirt called kammeesa ... As for the women, called choochis, they wore the traditional clothing of thuni" analogous to the male counterparts of the mundu and kavaya, the neckless blouse (Miranda 2013: 2). The protagonists "wore beaded gold chains called kotheenjas" (Miranda 2013: 3). Sajai Jose's translated version retains the regional names imparting the real quintessence of the region to the readers.

Analogous to her male counterparts Juana Mammanji dons the traditional clothing of women. She "wore the scapular called ventheenja ... blessed at the Arthungal church" and as per her belief wearing it made "easy for women to give birth; and it protected everyone from ghosts, spirits, demons, and fear" (Miranda 2013: 3).

Dressing, "articulates the body, framing the gender within a cultural context" (Kuhn 2005: 5). Clothing emerges as a signifier of communal history. It becomes associated with the ritualistic collective identity as each custom and occasion insists on following a particular dress code. The Cochin-Creole community regulation that "the dead were to be dressed in 


\section{Divya N.}

their wedding clothes" emphasizes a cultural code of historical enactment (Miranda 2013: 46). Dressing habits constitutes a self-regulation in adherence to the specific and collective identity formulation.

Ornaments and clothing accompanies the physical demeanour of the protagonists entailing a new hermeneutics of bodily identity connoting the postcolonial anxieties of domestic positioning. Accompanying accessories with dress comprising of specific models of gold chains and necklace constitute the subjective designing of an unconscious historical sense of collective bonding. The urge for a particular kind of communal visibility motivates protagonists like Mammanji to wear those accessories, articulating a certain semiotics of belonging.

Mammanji's walking etiquette furnishes a new mode of selfregulation. The physiognomic fashioning of Juana Mammanji and later Osha's Mamma, "clicking her fingers in a peculiar rhythm, dancing to the tune of a strange song which no one had heard before, sung in a melody on one could imitate, in words no one understood" signifies a historical uncanniness specific to religions and regions" (Miranda 2013: 10).

Descriptions of furniture, buildings and household articles peculiar to the Cochin-Creole community in Kerala constitute a universe of specific visibilities exemplifying an identity enactment. The object world in the narrative comprises of the "Thocha on which Mammanji used to light candles" meaning a type of candle stand used in churches and the "fuskya icons" or the religious icons framed in wood and glass" (Miranda 2013: 33). The narrative discusses the architectural magnificence of the Portuguese colonies exemplified in the church buildings like St. Andrews Basilica illustrating the fact that "The ecclesiastical architecture of Kerala also came to be influenced by Portuguese ideas and styles" (A. Menon1967: 234). 
Reading Community and Culture in Translated Fiction...

In short, the materialistic world in the narrative cohabited by objects and constituted by methods of embodying documents individual and communal history as cultural and social practices.

\section{Transcending Space and Time}

Physical and psychological journeys entail a new dynamics of shifting history. They become both metaphorical and literal in the perceptive framing of social and cultural history. Journeys to significant religious places become attributed to the individual historical and geographical sense, culminating in the creation of a new spatial sense of community. New spatial destinies generate diverse individual histories. Osha's fatherin-law's guilty conscience leads him to his pilgrimage to Velankanni where he confesses his guilty self while Ida's psychological disturbance culminates in her brief exile and coming back, culminating in death.

Religious journeys of the protagonists to the churches of St. Sebastian and St. Anthony depict their inclination to adapt into the Kerala native culture through a random and deliberate selfmodification. Osha's wife Jacintha and her mother visit the Saint of Edapally during "the first Friday of every month" (Miranda 2013: 30).

Spiritual voyages culminate in the temporal comprehension of the past and the present of the individual self in the spatial matrix of the native and alien places. Journeys of people like Thummai Chettan and Ida Chitta involve interior explorations into the uncertain terrains of their existence. Unsatisfactory personal lives and identity crisis motivate their journeys with physical dislocation entailing an exile and redemption from the past anguish and agony. Thummai chettan embarks on travelling due to his guilty mind resulting from his refusal to share the wealth with others and his subsequent loss while 


\section{Divya N.}

madness and psychological unrest due to her mother's incest with her husband motivates Ida's exile. "The motif of the journey, in other words, is intimately linked to an encounter with heterotopoi (other spaces) where the self-certainties of the subject are put into question" (Kumar 2002: 173).

\section{Language and Community}

Language becomes an open window enabling the historical gaze while bearing testimony to the syncretisation of culture. The narrative explores the immense social and cultural possibilities inherent in the poly-vocal nature of the hybridised language of the Cochin-Creole. The translation supports the novella's endeavour to communicate to the reader the language of the community by retaining the idiolects, dialects and sociolects. The translator observes that he had "decided that the first rendering should be literal and as faithful to the Malayalam as possible" (Jose 2013: xviii). The Series Editor's Note observes that "Having absorbed words from nearly four hundred languages, English is opulently equipped to interpret and express the cultural energy of the regions it once entered as the colonizer's voice" (Krishnan 2013: x). Perhaps this awareness might have encouraged the translation endeavours into English. An analysis of the employed Creole terms facilitates a deliberate dialogic interaction with the collective history of articulation.

The employment of language becomes relative and relational accentuating the collated affinities of a community. The incorporation of hybrid terms in the everyday communicative practice "like Nona (in Indonesian-Dutch, refers to a locally born Creole woman, believed to come from the Portuguese 'Senhora' for 'lady' or 'madam') and Choochi, apparently a version of Zusje (Indonesian Dutch for 'sister')," manifests a 
Reading Community and Culture in Translated Fiction...

distinguishing textual quality explicating the diverse cultural zones of existence (Devika 2013: xxviii).

Names like ventheenja- meaning the scapular and thochameaning candle stand illustrate the cultural transaction of "linguistic practices" between the European world and Kerala modernity, through the intersection of multiple temporal and spatial paradigms. Intersection of cultures constructs new forms and dynamics of communication. The Creole terms absorbed into the interior nuances of communication denote a heterogeneity and diversity furnishing the reader with a conspicuous historical sense of colonialism reinforcing the authorial belief in his "good fortune to be able to record, through ... writing a unique way of living and speaking that is being lost" (Miranda 2013: xii).

The narrative hints at the multiple possibilities and nuances in the employment of Cochin-Creole language facilitating an assimilation of the native tradition and culture. It acknowledges the fact that "Creole systems, while maintaining Portuguese traditions are also centred in the African and Asian cultural and linguistic spheres and impose them on the former, altering and assimilating their texts, thereby creating mutual breaches of the cultural spaces" (Jackson 1990: xiii).

\section{Women, Family History and Communal Identity}

Genealogy in the translated narrative reflects the communal identity with the women donning the defender role of history and religion. Acknowledgment of the imposed oppressed status binds the women in the narrative with their male counterparts.

Enactment of tradition and history becomes ostensible and indispensible for perpetuating "the chain of memory." After receiving Mammanji's chest, Osha's Mamma took "Mammanji's thuni, silk kavaya and shoe, kotheenja and hat, 


\section{Divya N.}

silver needle and brooch, necklace, amulet, and ventheenja, and wore them all elegantly and in their proper order" (Miranda 2013: 53). Mamma's retrieval of Mammanji's chest accompanies the transformation of her voluptuous manner into a "noble and serious looking choochi" capable of preserving and bearing tradition (Miranda 2013: 56). She deliberately reclaims her lost agency and voice in the domestic atmosphere after her eloping with Xavy, through the acquisition of Mammanji's chest, thus self -inducing and self-reverberating a historical continuity and tradition. Retaining of the names of clothes like kavaya signifies the translator's endeavour to transmit the regional culture into a global level through the portrayal of women.

Incidents like Mammanji's canonization by Vatican in the later part of the narrative constitute the elevation of the female protagonist into the role of the preserver of history. Mamma's apparently compulsive assertion of herself as the tradition preserver in the narrative mirrors her gendered desire for a "historical inclusion." Her perpetual longing for the communal recognition despite their earlier rejection and contempt of her distinguishes her seemingly self-enforced actions and motives. Despite the portrayal of the significant role played by the "marginal" women, in scripting the community history the narrator indeed subtly acknowledges the fact that "The ideologies of women as carriers of tradition often disguise, mitigate, compensate, contest, actual changes taking place. Womanhood is often part of an asserted or desired, not an actual cultural continuity" (Sangari \& Vaid 1990: 17).

Mammanji and mamma act as the guardians of religion and community through acts of compulsive insistence on the community members to pray and recite works like "the Puthenpaana in their homes on Good Friday" (Miranda 2013: 7). Mammanji's miraculous acts during her ecstatic trance 
Reading Community and Culture in Translated Fiction...

comprising of her lying "belly down on the dishes set on the table," astonishing physical metamorphosis, epiphanies and predictions resemble those of the Marina of Aguas Santas as her instructive, predictive predilections become symptomatic and connotative of the male missionaries (Miranda 2013: 10). Her performance of miracles becomes instances of unconscious self-exploration into the community history that had earlier endowed and believed in the supreme "special" powers of religion and faith. Analogous to Mamma's deeds they indeed stem from her unconscious desire for social recognition from a society that had always seemingly attached significance to men as creators of history. She becomes a religious scrutinizer and observer as "On her way, she would stare at each and every one, checking if everyone was wearing their ventheenjas" or the religious necklace and would spit at people without it (Miranda 2013: 10). She "would scold those who were lazy about attending prayer and church, those who slept at those times without observing esthi" meaning the conventions supposed to be followed during rituals (Miranda 2013: 10). Mammanji's healing powers further enhances her protective role. Her esoteric healing ways and alternative medicines include "cure for inflamed tonsils", mumps, jaundice and post-delivery rituals constitute the method of colonial belief intermingling theology and science. The healing methods comprised of seemingly strange practices as "for mumps, the prescriptions included hanging a coconut shell around the neck and beatings with the courtyard broom" (Miranda 2013: 8). In fact Juana Mammanji assumes the role of a female saint through the construction of an assumption of being the "chosen one" in the community. Her religious foreordination and predictive assuming entails a visionary prospect for the Cochin creoles and their futuristic hopes. The translation supports the novelist's representation of the women in the community. 


\section{Divya N.}

Historical continuity becomes constantly bound with selfarticulation and the female protagonists emerge as the story tellers of their community. Jacintha's story about her father Thummai chettan and his sinking pot of gold becomes a historical foil to Osha's quest for the lock of the key as the sinking pot in the narrative bears the semantics and semiotics of a dying history. Stories and myths articulated by Mammanji and Mamma constitute a lost memory.

Contrary to the male protagonists the female figures in the translated narrative emerge as more resilient in perpetuating the past. They embark on the role as the signifiers and signified in the semantics and semiotics of the cultural past. "Osha's and Ida's mother seems to possess the uncanny ability to re-enter the community ... leaving behind her earlier self completely. And this is in sharp contrast with Osha's experience of ... leaving the community through marriage" (Devika 2015: 12-13). Osha's psychological dilemma and identity crisis becomes juxtaposed with Jacintha's and Mamma's certainty of their communal identity and subjective positioning in the collective framework. The authorial intervention further entails a simultaneous positioning of Osha's Pappa's negation of past and ancestry with the contradictory attitude of historical indebtedness and awareness of Mamma.

Family constitutes the fundamental paradigm on which the individual builds his historical sense. It figures as a conglomeration of individual subjectivities encapsulating diverse characters in the single matrix of existence. Osha's marriage with Jacintha and her subsequent pregnancy connotes the beginning of another miscegenated race as Jacintha belongs to the community of "Mappila Latin Christians, who wore thrice-washed white full-blouses and mundu, and fingerthick ear rings in their upper ears" (Miranda 2013: 30). 
Themes of incest and sin dominate the historical and fictive conceptualisation of family. Unaware of the insidious intentions of Xavy Mamma elopes with him leaving Ida her daughter who is Xavy's wife in a psychologically shattered condition and returns home after facing exploitation and trafficking in his hands. The incestuous relationship between Xavy and Mamma in the narrative proves instrumental in the disintegration of Osha's family structure as his Pappa embarks on a relationship with another lower caste woman for sexual satisfaction and ends up murdering a psychotic and pregnant Ida. Mother's moral fallibility and deceit transgressing the historically and communally approved rules contribute to the psychological degeneration of Ida and the dissolving of family structure.

\section{Selfhood and History}

The translated novella differs from the literary precedence of early community novels through its accentuation on the individual perception and a subjective vision of history. The aspects of progressive and regressive selfhood in the narrative become instrumental in the synchronising of the past and the present, conceptualising history in the fictive intersectional framework of traditional modernity or modernised tradition.

Historical alterations become inextricably associated and interwoven with the "self- uncertainty" and the identity conflict of the protagonists like Osha caught between the pressure to appropriate according to the Kerala culture and the struggle to retain his specific identity. The consciousness of the past dominates the psychological exploration and the legitimatizing of the present of the protagonists. Osha the narrator consciously and unconsciously inclines to articulate history. His loss of mobility and response symbolises the end of a family history that becomes stagnant as he tells "I heard 


\section{Divya N.}

everything. Knew everything ... I had only lost my ability to move, and to respond" (Miranda 2013: 72). The physical impairment of Osha becomes juxtaposed and contradicted with his cognitive awareness constructing a historical and collective sense.

Subjective accounts furnish an inevitable visual portrayal of the community history of the Parankis, the miscegenated race in Cochin with the characterisation implying a positioning of the individual selfhood in the collective historical identity. The introducer's name is Josy Pereira and is addressed as Osha. The names of his father, mother and ancestors are Franso Pereira, Petrina Pereira, Caspar and Juana. Names in the narrative symbolises Portuguese affinity and identity.

The narrator explicates Juana Mammanji’s nickname as Judge Nona and her multiple roles in religious and medical healing comprising of the enactment of mid-wife profession in the context of the pre-delivery rituals in Christian community. The retrospective narrative glance captures Mammanji's introspective self as she lived in solitude "reading the Holy Bible in the light of the hurricane lamp" (Miranda 2013: 11).

Individual disposition towards the collective existence moulds the protagonists' subjectivity. The narrator's father Franso Pereira depicts his hatred toward his own community called Parankis and his sacristan work in the church which surprises Osha or the narrator. His contempt towards his own CochinPortuguese community becomes indicative of the protagonist's hatred of his roots. A close scrutiny of the characters discloses their rejection of the proposed pride on their colonial ancestors. The characters represent and accentuate the deplorable plight of the descendants of the Cochin Portuguese after the decline of the Portugal colonial rule in Kerala. According to Osha "So what if we call ourselves Parankis and 
Reading Community and Culture in Translated Fiction...

have these surnames, none of us knows English, nor have trousers or coats or shoes" (Miranda 2013: 12).

Community memory unfolds through individual reminiscences. Stories and myths perpetuate the past occurring as refrains. Thummi chettan or Osha's father-in-law's story of the missing pot that goes deeper into the pit on digging entails another framework of historical discontinuity as it epitomises a submerging past, embracing erasure and extinction. The written lives of the Cochin creoles in the narrative parallel and parody their historical degeneration after the setting of the Portugal rule in Kochi.

\section{Faith, History and Fiction}

Analogous to the framework of community, faith forms a source of identity and belonging in the translated narrative. The translated narrative retains the Malayalam title with the word "oppees," implying a tribute for the community past and old beliefs, for the sake of the living members. Religion reconstructs the sacred topography of historical belief with the emergence of faith as a colonial-critique mode of the past. Belief emerges as one of the central concerns and key factor in the "narrative fictionalising" of history. Explicit and implicit references to the "religious history" of Kerala occupy the narrative. Rituals and festivals form occasions for collective participation and historical re-enactment of the past. In fact "popular religious practices, it has been seen, sometimes become a resource for emancipation" (Mohan 2008: 370). The narrative embodies the rich palimpsest of customs layered into the Creole existence acknowledging the fact that "Life for the coastal people of Kochi is but a passionate commingling with rituals and customs" (Miranda 2013: xii). Justifying the authorial note, Osha elucidates that "During the days of Lent, there is a ritual of calling Devastha in the coastal region" 


\section{Divya N.}

where Devastha refers to the custom where religious volunteers go to the houses under the church counselling people to pray (Miranda 2013: 7). Large scale community participation and celebration occur in the "night of the vespera of St. Sebastian's kombreria festival at the parish church" with vespera meaning the evening prayer and kombreria referring to the mass gathering for celebrating the feast (Miranda 2013: 18). Discussions and descriptions of the popular religious festivals in the narrative connote the social practices enabling the subjective locating of the individual in the historical collective.

Stories and myths pertaining to festivals dominate the cumulative historical unconscious. The story of the Saint of Arthungal who "unleashed a terrible pox on the locals" for their refusal to vacate homes for the pilgrims to the Arthungal church and the figures of Saint Kuriakaose, Elias Chavara constitute the religious sphere of a mythical past (Miranda 2013: 4). The author's articulation of the Paranki beliefs constitutes a "collective memory" employed "to illuminate the historical past" (Mohan 2008: 369). Discussions on the relevance attributed to "the first Fridays of every month" where Mammanji "would wear a glittering new silk kavaya ... [and] put on her kotheenja, a silver bangle, a string with a gold cross on it, a scapular tied with holy remains, the shoes called sappath, and finally fix a large hat on her head" and the "Maundy Thursday" occupy the textual space of the narrative (Miranda 2013: 9).

The personalised religion is relegated to the community sphere as the individuals become entrusted with the task of redeeming and flourishing their tradition and past. All the protagonists are closely associated with church. The male family members of Osho are sacristans meaning assistants of the Vicar in the church. 
Themes of conversion and identity dissolution in the narrative suggest the "Latinisation of Kerala Church." According to Osha "When the coastal people -the lowest of low in wealth, education, caste, and living standards -were converted, all that they were really given were some four hundred surnames" (Miranda 2013: 12-13). "The Portuguese considered it their duty to substitute the supremacy of the Pope of Rome over the Kerala church for that of the Patriarch of Babylon and to replace the Syrian liturgy by the Latin liturgy of the Roman Catholic Church" (A. Menon 1967: 238). Osha's marriage with Jacintha, a "Mappilah Latin Christian" signifies the increasing possibilities of complete Latinisation and dissolution of the family identity in the Latin church.

The community history of Cochin creoles had been fraught with stories of religious conversion. The Portuguese had endeavoured to reinforce the religious conversion of the natives irrespective of their caste positions. Christianity proved to be a refuge to the lower-caste natives as it elevated their "subaltern" position, facilitating their emancipation in the mainstream public sphere. The protagonists echo the significant fact that "In Kerala, in particular, Christianity was the interface through which lower castes experienced modernity. And it was Christianity that allowed for their entry into a public sphere generated by inter-religious discussions" (D. Menon 2002: 1663).

Osha's father embodies the hatred against the compulsive submerging endeavours into the Catholic Church, aimed at other sects inside the Christian religion while attempting to homogenize the Christian identity. "When there was no one in the church" he addresses Christ as "Jooda Kazhuvery" referring to Jesus' Jewish origin (Miranda 2013: 13). His hatred towards the Jewish ancestry of Christ ironically comprises of his own unconscious disinterestedness towards 


\section{Divya N.}

his own community that bears the traces of multiple Eurasian cultures and lineage probably including that of Jews. It is observed that 'Osha's father's rebellion against the Catholic Church is silent and mostly self-destructive ... [as] he whispers abuse on Christ -Jooda kazhuverry [where] Jooda refers to Jesus' Jewish birth -and thus turns (Christian) anti-Semitism against Jesus himself” (Devika 2013: xxxi). Franso's act in fact portrays Christianity as "the most syncretistic of the great faiths, while never losing the marks of its Jewish origins" (Walls 1997: 59).

Osha's recurring dream of a pig with the man's face whose "anus would dilate rapidly like the mouth of a volcano and explode with a loud blast, spraying the animal's intestine and filth all over" on being slaughtered signifies his anxiety towards his disappearing community as pork formed an indispensable food item in his community households during functions and feast (Miranda 2013: 51). The narrative "unfolds an extraordinary, intriguing tale of the community's slow merging into the bosom of the Roman Catholic Church, a dirge at its impending disappearance" (Devika 2013: xxx).

Desire for retaining the old specificities and maintaining heterogeneity accompanies the religious conversion. Family practices like reciting the special prayer, seemingly undecipherable to the world and comprehensible only to the family implies certain inclusiveness and circumscribing of the religious tradition within the family. The loss of "old, soiled, yellowed scraps of paper ... like a holy relic" from Franso coincides with the loss of the key by Osha (Miranda 2013: 25). The missing religious paper in the narrative bears an esoteric or occult aura connoting the deprived roots of the protagonist thus foregrounding their historical quest for the lost past. 
Reading Community and Culture in Translated Fiction...

Narrative references to religious and historical works like Puthenpaana, Vanakkamaasam, Mar Alleshucharitham, Genoaparvam, Istakicharitham composed chiefly by European missionaries and their perseverance in the household signifies the inclination to resuscitate a lost immigrant history and past. Religious historicity inculcates and encourages a new sense of individual past that is simultaneously collective and subjective. The authorial portrayal of the subjective consciousness of the protagonists Osha, Jacintha, Mammanji etc., bears implicit and explicit nuances that transform the seemingly invisible and marginalised history into a collective visible paradigm.

Consistent spiritual self-reflections of the protagonist Osha render a ontological spectrum to the collective memory embedded in the fictive text. His delineations of religious customs pertaining to death and birth supplement an empirical verifiability of the communal history.

The author ventures to inculcate a mnemonic aura of religiosity in the narrative framework. The titles of the sections bear a unique historical sense of religiosity. Names of sections like "The Curse of God upon the Sacristan", "A Church bell that had never been Rung" etc., generate an archival religious feeling and a historical consciousness. The employment of religious idioms throughout the narrative suggests the religious rootedness of the colonial history occurring due to the inextricable link between faith and colonial history.

Acts of blasphemy and religious irreverence form the historical counter narrative.

Juana Mamaanji persistently tells Franso during her last days that "you have the curse of God upon you" implying his loss of identity and belonging (Miranda 2013: 22). Franso Pereira's blasphemous acts of abusing Christ and fixing "a lit beedi in 


\section{Divya N.}

the hand of the "idol of St. Anthony in the cupola" frames his desecration towards the religious past (Miranda 2013: 23). His loss of eye becomes allegorical of the individual's lost vision of past.

Inebriation of the vicar Father Varghese who bought two bottles of kottodi which is a strong local drink "and drank it mixed with water and coconut water before dinner" is juxtaposed with the blasphemy of Osha's father, a sacristan (Miranda 2013: 26). Religious degeneration evolves with the individual neglect of history and memory.

Church as a spiritual institution in the narrative encompasses collective history and identity symbolising individual inclusiveness in the communal framework. Personal belief in salvation progresses in pursuit of an unconscious compulsive obligation with the communal practice of attending prayers and masses. Protagonists like Mammanji, Mamma and Jacintha believe in the individual commitment to the church, in the form of regular attendance and emancipation in the rituals and activities of church. According to the narrator, the Cochin Creoles "like nothing better than to attend as many masses as possible before they died and enter them all in the ledger of life" (Miranda 2013: 28). Belief in the collective immanent will and acknowledgement of a "universal" presence in the individual destiny guides their subjective faith.

\section{Translated Narrative's Landscape of History}

The translated narrative renders the cultural and social history of creoles through a kaleidoscopic portrayal of their lost past and history. The fictive landscape uses the psychological trope of the lock and key that emerges as community metaphors of historicity. The grave in the narrative becomes symbolic of the buried history while the key connotes the memory that enables the unlocking and subsequent unearthing of the past. The 
Reading Community and Culture in Translated Fiction...

protagonists including Osha immerse themselves in the historical imagination of future while framing their memories in a glorious past associating their individual destinies with the cultural and historical fate.

The narrative structures a voice of resistance against the homogenising of the marginal identity. Memory evolves into a tool that enables the prevalence possibilities in alternative historical paradigms of the marginalised. It presumes and entrusts itself with the task of "bringing to the fore the identity of the Paranki over those of the Luso- and Anglo-Indian. It hints that there are other, more subaltern, voices that may be further marginalized in and through the move to recast the community as "Luso-Indian" (Devika 2015:14)

However, the fictive element of the novella sustains in the historical imaginative rendering due to the authorial realisation that "the purpose of the art form that is the novella, is not the documentation of a society ... To do that, a historian or an essayist ... would be far more qualified to do it than a writer of fiction" (Miranda, 2013:xii-xiii). Hence, the novella "Requiem for the Living does not seek to be a substitute for anthropological description. Nor is it a simplistic attempt to claim and assert a community identity - and indeed, this is what marks it as a unique literary effort" (Devika, 2013: xxix).

Analogous to the author the translator too has played a vital role in the cultural transmission endeavour, recognising the fact that "Translation into English brings together the creative potential of different Indian languages, the special understanding of the world each one of those languages has, and consequently, the distinctive way they carry the memories and histories of those who use them" (Krishnan, 2013: x).

So far I have interrogated, propounded and outlined the multiple dimensions associated with the recasting of history in 


\section{Divya N.}

the fictive mould of the translated text. I had endeavoured to argue that the individual or subjective memory constitutes the cumulative essence of identity with the aspects of language and religion constructing the cultural angle.

My paper explores the manifold and heterogeneous ways inherent in the portrayal of a collective past inside the rubric of the translated text. Fictive transformation of history in the translated text emerges as the key concern of my academic exploration. The interrogation subsequently delineates the multiple dimensions inherent in the transfer of the community history from the "real" landscape into the textual environment of "logo-centrism."

Mnemonic ruminations in the context of collective identity form the fulcrum of the analysis. Diversions, discrepancies and disjunctions in the subjective recasting of communal memory become another major praxis in this study. The researcher that is I sincerely hope to have achieved the objective of building my argument, accentuating the fact that history and language are the keys that enable the constructive perception of individual and collective human identity.

\section{References}

\section{Primary Reference:}

MIRĀṆẠ, JOHNY. 2013. Jeevichirikkunnavarkku Vendiyulla Oppees: Requiem for the Living (Sajai Jose Trans.). New Delhi: Oxford University Press.

\section{Secondary References:}

BAKHTIN, M. Michael. 1981. The Dialogic Imagination: Four Essays ed. by Michael Holquist. tr. by Caryl Emerson \& Michael Holquist. Austin: University of Texas Press. 
Reading Community and Culture in Translated Fiction...

DEVIKA, J. 2013. Introduction. in Miranda, Johny. Jeevichirikkunnavarkku Vendiyulla Oppees: Requiem for the Living. New Delhi: Oxford University Press. xxi-xxvii.

DeviKA, J. 2015. Cochin Creole and the Perils of Casteist cosmopolitanism: Reading Requiem for the Living. The Journal of Commonwealth Literature 50(3). 127-144. doi:10.1177/0021989414563150

JaCKson, Kenneth DAVID. 1990. Preface. In K. D. Jackson. Sing without Shame: Oral Traditions in Indo-Portuguese Creole Verse: With Transcription and Analysis of a Nineteenthcentury Manuscript of Ceylon Portuguese. Benjamins and Instituto Cultural De Macau: Amsterdam. xi--xxviii.

Jose, SAJAI. 2013. Translator's Note. In Johny Miranda. Jeevichirikkunnavarkku Vendiyulla Oppees: Requiem for the Living. New Delhi: Oxford University Press. xvii-xix.

Krishnan, Mini. 2013. Series Editor's Note. In Johny Miranda. Jeevichirikkunnavarkku Vendiyulla Oppees: Requiem for the Living. New Delhi: Oxford University Press. ix-X.

Kuhn, Cynthia G. 2005. Self-fashioning in Margaret Atwood's Fiction: Dress, Culture, and Identity. New York: Peter Lang. KUMAR, UDAYA. 2002. Seeing and Reading: The Early Malayalam Novel and Some Questions of Visibility. ed. by Meenakshi. Mukherjee. In Early Novels in India. New Delhi: Sahitya Akademi. 161-192.

Menon, A Sreedhara. 1967. A Ssurvey of Kerala History. Kottayam: Sahitya Pravarthaka Co-operative Society; National Book Stall.

Menon, DileEP. 2002 April 27. Religion and Colonial Modernity: Rethinking Belief and Identity. Economic and Political Weekly 37(17). 1662-1667. Retrieved January 5, 2016.

Mohan, Sanal. 2008. Searching for Old Histories': Social Movement and the Project of Writing History in TwentiethCentury Kerala ed. by R. Aquil \& P. Chatterjee In History in the Vernacular. Calcutta: Permanent Black. 357-390. 
Divya N.

SANGARI, KUMKUM.; and VAID, SURESH. 1990. Recasting Women: An Introduction. In Recasting Women: Essays in Indian Colonial History ed. by Kumkum. Sangari \& Suresh. Vaid. New Brunswick, NJ: Ruutgers Press. 1-26.

Thomas, Suresh. P. 2014 December 4. The Kochi Novel. Fountain Ink. Retrieved January 5, 2016.

Walls, Andrew. 1997. Christainity. In A New Handbook of Living Religion. ed. by John. R. Hinnels. London: Penguin Books. 55-161. 